\title{
CircRNA: A novel potential strategy to treat thyroid cancer (Review)
}

\author{
GUOMAO ZHU ${ }^{1,2^{*}}$, XINGYU CHANG ${ }^{1,2^{*}}$, YUCHEN KANG $^{3}$, XINZHU ZHAO $^{1,2}$, \\ XULEI TANG ${ }^{1,2}$, CHENGXU MA ${ }^{1,2}$ and SONGBO FU ${ }^{1,2}$ \\ ${ }^{1}$ Endocrinology Department, The First Hospital of Lanzhou University; \\ ${ }^{2}$ Endocrine Disease Clinical Medical Research Center of Gansu Province, The First Hospital of Lanzhou University; \\ ${ }^{3}$ The Second Clinical Medical College, Lanzhou University, Lanzhou, Gansu 730030, P.R. China
}

Received June 7, 2021; Accepted September 2, 2021

DOI: $10.3892 /$ ijmm.2021.5034

\begin{abstract}
Thyroid cancer (TC) is the most common type of endocrine cancer. Over the last 50 years, the global incidence of TC has been increasing. The survival rate of TC is higher than that of most other types of cancer, but it depends on numerous factors, including the specific type of TC and stage of the disease. Circular RNAs (circRNAs) are a new class of long noncoding RNA with a closed loop structure that have a critical role in the complex gene regulatory network that controls the emergence of TC. The most important function of circRNAs is their ability to specifically bind to microRNAs. In addition, the biological functions of circRNAs also include interactions with proteins, regulation of the transcription of genes and acting as translation templates. Based on the characteristics of circRNAs, they have been identified as potential biomarkers for the diagnosis of tumors. In the present review,
\end{abstract}

Correspondence to: Professor Songbo $\mathrm{Fu}$, Endocrinology Department, The First Hospital of Lanzhou University, 1 Donggangxi Street, Lanzhou, Gansu 730030, P.R. China

E-mail: fusb@lzu.edu.cn

${ }^{*}$ Contributed equally

Abbreviations: TC, thyroid cancer; circRNA, circular RNA; miRNA, microRNA; MSC, mesenchymal stem cell; PTC, papillary thyroid carcinoma; ATC, anaplastic TC; UTR, untranslated region; CDR1, cerebellar degeneration-related protein 1; RBP, RNA binding proteins; CTNNBIP1, $\beta$-catenin interacting protein 1 ; TCF, T cell factor; RNA pol II, RNA polymerase II; DNMT1, DNA methyltransferase 1; IRES, internal ribosome entry site; m6A, N6-methyladenosine; TME, tumor microenvironment; EV, extracellular vesicles; KLF6, Krüppel-like zinc finger transcription factor 6; LMO4, LIM-only protein 4; AMPK, adenosine monophosphate-activated protein kinase; CDK, cyclin-dependent kinase; EMT, epithelial to mesenchymal transition; LDLR, low-density lipoprotein receptor; ATP, adenosine triphosphate; TGF, transforming growth factor; LNM, lymph node metastasis; AUC, area under receiver operating characteristic curve

Key words: thyroid cancer, circRNAs, mesenchymal stem cells, exosomes the function and significance of circRNAs and their potential clinical implications for TC were summarized. Furthermore, possible treatment approaches involving the use of mesenchymal stem cells (MSCs) and exosomes derived from MSCs as carriers to load and transport circRNAs were discussed.

\section{Contents}

1. Introduction

2. Functions of circRNAs

3. Regulation of circRNAs in TC

4. Clinical application prospect

5. Future directions and conclusion

\section{Introduction}

The pathogenesis of thyroid cancer (TC), the most frequent type of endocrine cancer, is related to a variety of gene mutations, such as those in v-raf murine sarcoma viral oncogene homolog B1 (BRAF), human telomerase reverse transcriptase promoter, TP53 and NRAS. However, almost no gene mutation has been proven to be able to guide treatment or influence clinical outcomes (1). In addition to age, sex, ethnicity and residential region of patients and subjects with a family history of TC, radiation exposure, obesity, smoking and even body height may be risk predictors of TC (2). In the last decade (2007-2016), the incidence of TC rose at an annual rate of $23 \%$ among 20- to 39-year-olds and 4\% among 15- to 19-year-olds. The 5-year survival rate of TC $>99 \%$ (3) is related to numerous factors, including the unique type of TC (4), therapeutic treatment and overdiagnosis $(2,5)$. According to the origin and histological characteristics of cancer cells, TC may be divided into the following types: Differentiated TC, originating from follicular cells, which accounts for $>90 \%$ of all cases of TC (6) and includes two major subtypes, papillary thyroid carcinoma (PTC) and follicular thyroid carcinoma; cancer originating from parafollicular cells is known as medullary thyroid carcinoma. However, anaplastic TC (ATC), the most heterogeneous tumor type among all TC subtypes, accounting for $1 \%$ of TC cases, is the cause of the majority of all TC-associated deaths 
and the chance of a cure is slim (7). In South Korea, the prevalence rate has increased 15-fold over the past decade, which may be related to overdiagnosis due to thyroid ultrasound examination, while the TC-related mortality rate has been stable (8). Although fine-needle aspiration biopsy is the gold standard for TC diagnosis, its invasiveness limits its application; therefore, there is an urgent requirement for a novel, less invasive method to balance the specificity and sensitivity to improve the accuracy of TC diagnosis.

Circular RNAs (circRNAs) are a new class of noncoding RNA (9) that are generated from linear precursor mRNAs in a nonclassical splicing square, which endows them with a unique closed continuous ring structure. According to their composition, circRNAs may be divided into three major types, the most common being exonic circular RNAs (ecircRNAs), and the others being circular intronic RNAs and exon-intron circular RNAs (EIciRNAs) (10). Based on recent studies, circRNAs have the following distinct features: i) Multiplicity: Different genes are able to encode circRNAs with different combinations of exons and introns due to alternative splicing (11); ii) Abundant expression: In fibroblasts, $14 \%$ of the transcribed genes are made up of circRNAs and the expression is much greater than that of their linear host RNAs (12); iii) Stability: CircRNAs are stable due to the lack of 5'-3' polarity and a polyadenylated tail and they accumulate in numerous cell types, such as neural tissues, $(13,14)$; iv) Conservation: In mammals, circRNAs are likely to have a higher sequence conservation than other types of RNA (15). These features of circRNAs indicate their varied potential biological functions and clinical applications. CircRNAs are currently known to regulate gene expression directly or through interaction with micromolecules to process various biological functions accordingly (Fig. 1).

\section{Functions of circRNAs}

Due to their capacity to broadly regulate cell conditions, circRNAs may be associated with tumor progression. Abnormal expression of circRNAs has been detected in numerous cancer types, such as esophageal cancer (16), gastric cancer (17), colorectal cancer (18), hepatocarcinoma (19), glioma (20), bladder cancer (21) and TC (22). CircRNAs function as cell activity regulators, mainly through the following four aspects discussed below.

miRNA sponging. MicroRNAs (miRNAs) are single-stranded noncoding RNAs 22 nucleotides in length and mediate post-transcriptional gene silencing in the cytoplasm by interacting with the $6 \mathrm{nt}$ seed sequence on the 3'-untranslated region (3'UTR) of their target mRNAs $(23,24)$. miRNAs have extensively vital roles in the post-transcriptional regulation of gene expression, including cell proliferation, migration, differentiation and apoptosis (25-31). Serving as the upstream molecules of miRNAs, circRNAs, which contain miRNA response elements, are able to bind various miRNAs and suppress their activity via a mechanism known as miRNA sponging $(30,31)$. For instance, the first discovered miRNA sponge, antisense transcript of cerebellar degeneration-related protein 1 (CDR1), also termed CIRS-7, derived from the antisense transcript of the CDR1 gene, is able to negatively regulate miR-7 $(30,31)$, which may be detected in gastric cancer and hepatocellular carcinoma $(32,33)$. This effect is also commonly observed in TC: CircFAT1 (e2) has a function similar to that of CIRS-7 and has a binding site for miR-873. CircFAT1 is highly expressed in PTC tissues and cells and serves as an miRNA sponge to vastly downregulate miR-873 expression, thus upregulating the activity of zinc finger E-box binding homeobox 1 and ultimately promoting the growth, migration and invasion of PTC cells (34).

Protein interaction. In addition to miRNA sponging, protein interaction is another important function of circRNAs. Among other proteins, RNA binding proteins (RBPs) are the most famous proteins involved in the regulation of RNA metabolism in different fields, such as formation, transportation, localization and translation (35). Errichelli et al (36) reported that fused in sarcoma was able to modify the formation of numerous circRNAs in mouse motor neurons derived in vitro by binding the introns flanking the back-splicing junctions. Sharing consensus sequences with other RBPs, the c-MYC protein is able to interact with circ-Amotl1, easing nuclear translocation of c-MYC, which appears to promote its stability and upregulate c-MYC targets (37). Similarly, nuclear translocation of signal transducer and activator of transcription 3 is also associated with circ-Amotl1 in a parallel manner (38). In addition, numerous circRNAs have been reported to interact with proteins in TC. CircRNA_102171 is highly expressed in PTC tissues, directly interacts with $\beta$-catenin interacting protein 1 (CTNNBIP1) and obstructs its association with the $\beta$-catenin/T cell factor (TCF)3/TCF4/lymphoid enhancer factor 1 complex to facilitate PTC progression (39). Existing evidence affirms that specific circRNAs are able to interact with different proteins $(9,40)$, while certain proteins may also dynamically bind to different circRNAs $(41,42)$. To date, research on circRNAs interacting with proteins in TC remains limited, probably due to it being more challenging to analyze the binding sequences of circRNAs in RBPs than those of mRNAs.

CircRNAs regulate gene expression. Through an intricate mechanism, circRNAs are able to modify gene transcription. With the assistance of U1 small nuclear ribonucleoproteins, exon-intron circular RNAs (EIciRNAs) influence the activity of RNA polymerase II (RNA pol II) via RNA-RNA interactions and then regulate the transcription of their parental gene, ultimately affecting protein translation $(9,43)$. The nuclear circRNAs EIciPAIP2 and EIciEIF3J promote parental gene transcription in a similar manner (43). In addition to long non-coding RNAs, ciRNAs may also act as activators of RNA pol II and upregulate gene transcription. For instance, ci-ankrd52 enhances the expression of ankyrin repeat domain 52 protein (44). Certain circRNAs have the capacity to regulate gene expression at the translation level, in addition to the transcription level. Recently, Wu et al (45) reported that circYap impaired the interaction of PABP on the poly(A) tail with eIF4G on the 5'-cap of Yap mRNA. As a consequence, circYap suppressed gene translation at the initiation stage. It was also demonstrated that circRNAs may be associated with DNA modification. DNA methyltransferase 1 is a methyltransferase that controls DNA methylation and its promoter may be downregulated by circFECR1. Furthermore, circFECR1 is also 


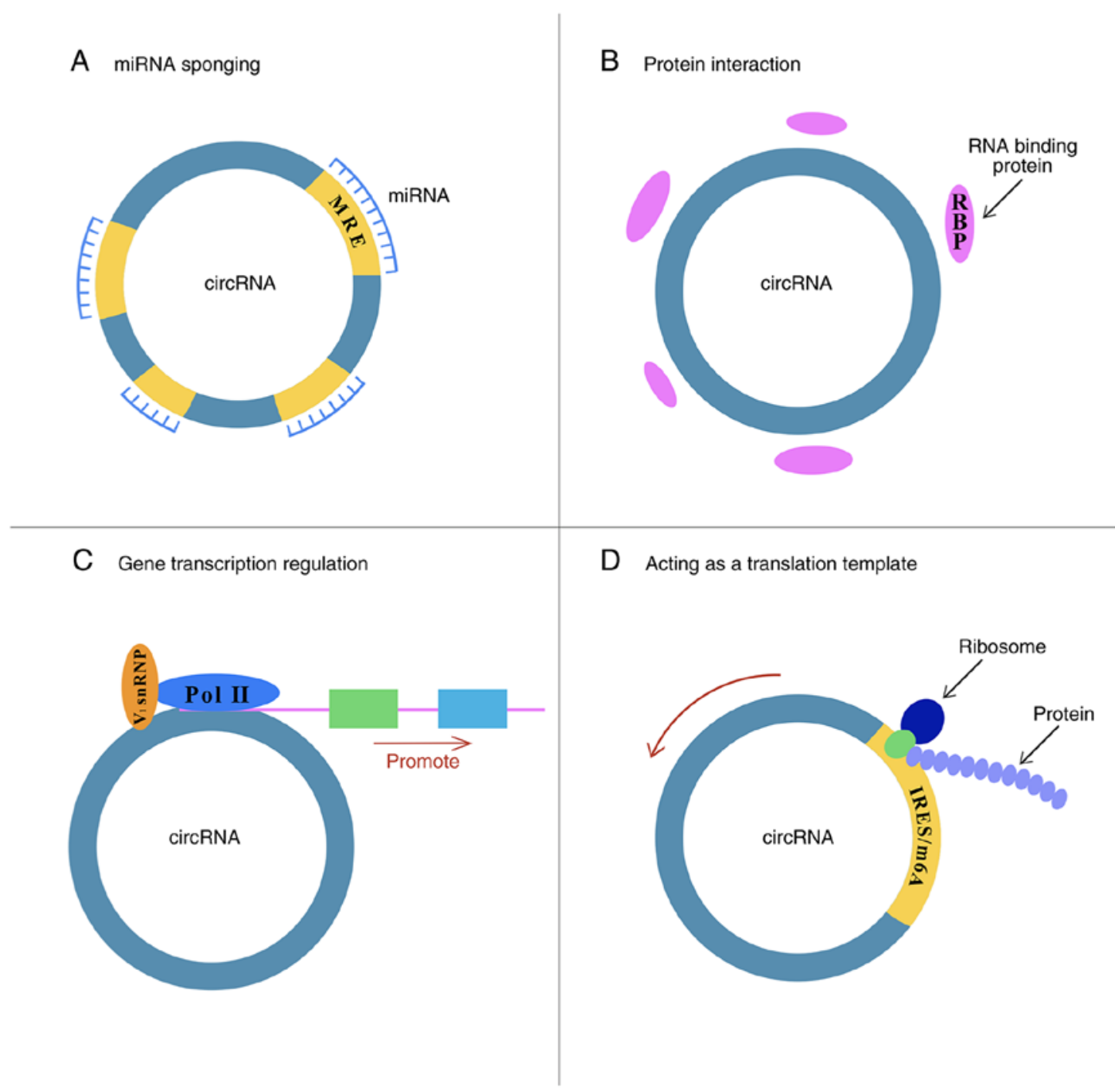

Figure 1. Functions of circRNAs. (A) miRNA sponging; (B) Protein interactions; (C) Gene transcription regulation; (D) Acting as a translation template. miRNA, microRNA; circRNA, circular RNA; POL II, RNA polymerase II; snRNP small nuclear ribonucleoprotein; RBP, RNA binding proteins.

able to recruit the demethylase TET1 to the Friend leukemia virus integration 1 promoter, resulting in the demethylation of DNA (46). As a consequence, circRNAs may regulate gene expression in different ways, while the effect of circRNAs on DNA replication remains unexplored.

Translation template. The two ends of a circRNA are connected by one covalent bond, which impairs its translation function. Furthermore, due to their loop structure lacking a $3^{\prime}$ and 5'UTR, circRNAs have been classified as noncoding RNAs. However, most circRNAs are ecircRNAs with an open reading frame, which implies their translational potential (47-49). To date, their translational activity has been proven in diverse organisms (50). With regard to certain groups of circRNAs, specific elements are indispensable for cap-independent translation mechanisms for translation initiation, such as internal ribosome entry sites (IRESs) or N6-methyladenosine (m6A) (49). For instance, with the existence of an IRES and necessary splicing elements, circZNF609 may be translated into zinc finger protein 609 in a cap-independent way, but the translation activity is much lower than that of its linear counterpart (47). Another cap-independent translation mechanism for circRNA is m6A in the circRNA 5'UTR, which interacts with eIF4G 2 and eIF3A and recruits the $43 \mathrm{~S}$ preinitiation complex to trigger translation. m6A modification may be found in more than one-tenth of circRNAs, the level of which is associated with circRNA translation efficiency $(51,52)$. It has been inferred that rolling circle amplification may be a mechanism of enhancing the translation productivity of circRNAs, but this mechanism only produces long, repetitive peptides (53). Increasing evidence suggests the direct translation function of circRNAs $(54,55)$. However, the proteins encoded by circRNAs remained to be analyzed. Perhaps these proteins are persistently produced at low levels due to the resistance to degradation and low translation activity characteristics of circRNAs.

In conclusion, circRNAs may regulate downstream gene and protein expression through various mechanisms and have numerous unique advantages over other noncoding RNAs. Although circRNAs have better stability and longer half-lives than their linear transcripts, the possibility of circRNA degradation in their in vivo transport when they are used as a therapeutic intervention remains to be investigated. The effects of circRNA degradation on disease and the biological effects 
on surrounding cells and tissues require further study. Previous studies have revealed that circRNAs are more conserved among mammals than other RNAs (12), but of note, in-depth study and continuous discovery of novel circRNAs have indicated that numerous circRNAs expressed are species-specific and do not have any sequence homology (56).

\section{Regulation of circRNAs in TC}

Increasing evidence suggests that noncoding RNAs, including circRNAs, contribute to the formation of the tumor microenvironment (TME), communication between cancer cells and surrounding stromal cells (fibroblasts, immune cells, endothelial cells) and the impact of physicochemical parameters (57). Numerous studies have revealed that multiple functions of the TME may be influenced by circRNAs, not only in tumor invasiveness but also in tumor angiogenesis, epithelial to mesenchymal transition (EMT) and drug resistance $(57,58)$. Thus, circRNAs may regulate the progression of TC invasion and evolution through different approaches (Fig. 2).

Regulation of invasiveness by circRNAs. Regulating cell invasiveness is of great importance in tumor progression. In recent years, certain oncogenic circRNAs have been indicated to regulate the invasiveness of TC. The upregulation of circ-ABCB10 in TC is negatively correlated with the expression of Krüppel-like zinc finger transcription factor 6 (KLF6) (59), which encodes a series of proteins that engage in the regulation of cancer development through alternative splicing, suggesting that circ-ABCB10 may promote the proliferation and invasion of TC by targeting KLF6 (60). As mentioned previously, circRNA_102171 is able to directly bind CTNNBIP1 and activate the $\mathrm{Wnt} / \beta$-catenin pathway. Ultimately, upregulated circRNA_102171 enhances the invasiveness of PTC (39). In addition to directly interacting with proteins, circRNAs also promote the progression of TC by sponging miRNAs. For instance, overexpressed circBACH2 in PTC sponges miR-139-5p, which is able to interact with the LIM-only protein 4 (LMO4) 3'UTR, resulting in the inhibition of LMO4. Therefore, the invasiveness of PTC is enhanced $(61,62)$. Similarly, circRASSF2 is enriched in PTC. By downregulating miR-1178, circRASSF2 facilitates tumor growth and promotes invasiveness (63). To date, circ_0008274 (64), circ_0103552 (65), circ_FOXM1 (66), hsa_circ_0058124 (67), circ_FNDC3B (68) and circ_EIF3I (69) have been reported to participate in the regulation of different signaling pathways associated with the proliferation and apoptosis of TC cells.

Cell cycle. The cell cycle refers to the time interval, as determined by experiments, during which cells prepare and then equally replicate their genomes to form two daughter cells (70). Cancer is characterized by the abnormal activity of various cyclins that lead to uncontrolled proliferation of tumor cells (Fig. 3). The upregulation of circDOCK 1 in TC is accompanied by increased expression of cyclin D1 and downregulation of p53, which leads to an imbalance of cyclin-dependent kinase (CDK) activity and rapid growth of tumor cells (71). Zhou et al (64) indicated that the expression of hsa_circ_0008274 in PTC was upregulated following activation of the adenosine monophosphate-activated protein kinase (AMPK)/mammalian target of rapamycin

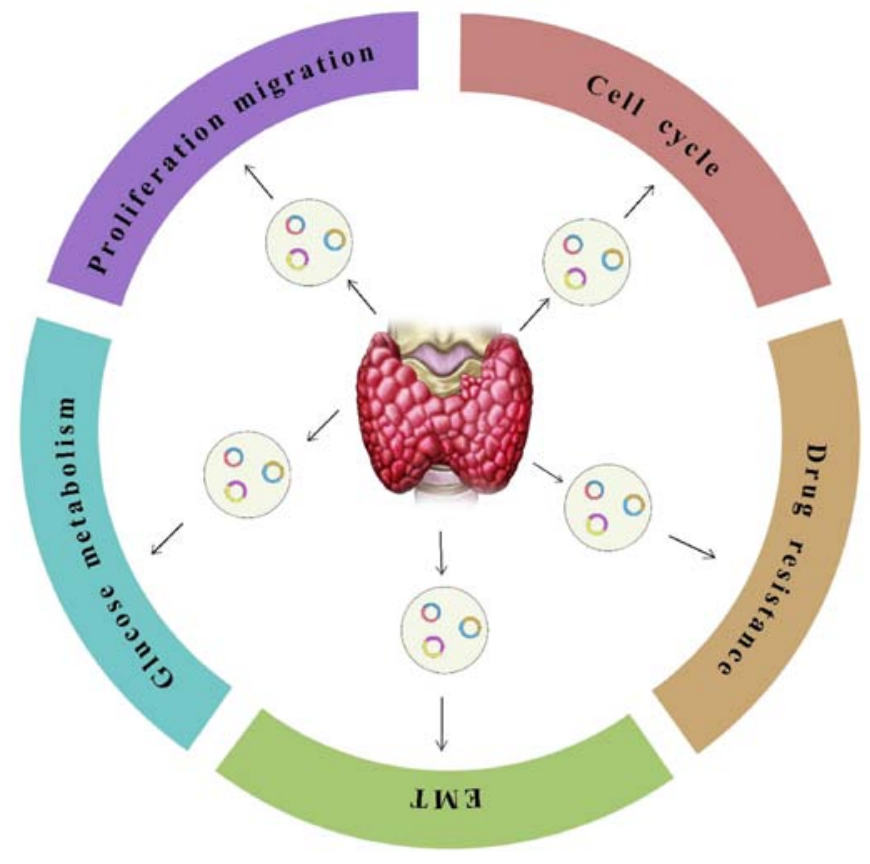

Figure 2.Functions of circRNAs in TC.CircRNAs are able to regulate TC progression through five aspects: Proliferation-migration (such as circRNA_102171, CircBACH2, circRASSF2, circ-ABCB10, hsa_circ_0008274, circ_0103552, circ_FOXM1, hsa_circ_0058124, circ_FNDC3B, circ_EIF3I), cell cycle (such as circDOCK1,has_circ_0008274,hsa_circ_0004458,hsa_circ_0011385),drug resistance (such as CircEIF6), EMT (such as circ_LDLR and circ_0067934) and glucose metabolism (such as hsa_circ_0011290). EMT, epithelial to mesenchymal transition; TC, thyroid cancer; circRNA, circular RNA.

signaling pathway. AMPK upregulates the p53-p21 axis and leads to cell cycle stagnation in G1/S phase (72). In PTC, circ_0004458 is upregulated. After circ_0004458 silencing, the cell cycle distribution was substantially decreased compared with that of the control group. Furthermore, hsa_circ_0004458 is able to regulate the expression of Racl through the specific sponging of miR-885-5p (73). Rac1 protein is able to activate extracellular regulated protein kinase $1 / 2$ signaling induced by $\gamma$-irradiation and the subsequent $\mathrm{G} 2 / \mathrm{M}$ checkpoint response (74). Circ_0001666 is highly expressed in PTC cells. After circ_0001666 downregulation, the cell cycle was blocked in G1 phase, decreasing the expression of cyclin D1 and cyclin E (75). When the overexpression of circ_PSD3 in PTC cells was abolished, the expression of cyclin D1 and CDK4 also decreased significantly, which inhibited the cell cycle progression of PTC cells (76). CircRNAs have a significant role in cell cycle regulation, bypassing cell cycle checkpoints in different ways to accelerate the progression of the cell cycle. Most current findings are from studies that performed knockout of cancer-promoting circRNAs and these types of experiments may reveal the effects of circRNAs on TC. The direct interactions between circRNA/miRNA or circRNA/protein and cell cycle proteins remain to be determined.

EMT. EMT is a process whereby epithelial cells lose their characteristics, such as cell-to-cell adhesion and cell polarity, and instead acquire interstitial characteristics during the process of cell culture; EMT is universally involved in physiological and pathological processes, particularly tumor metastasis (77-79). Therefore, analyzing the contribution of circRNAs to EMT and 


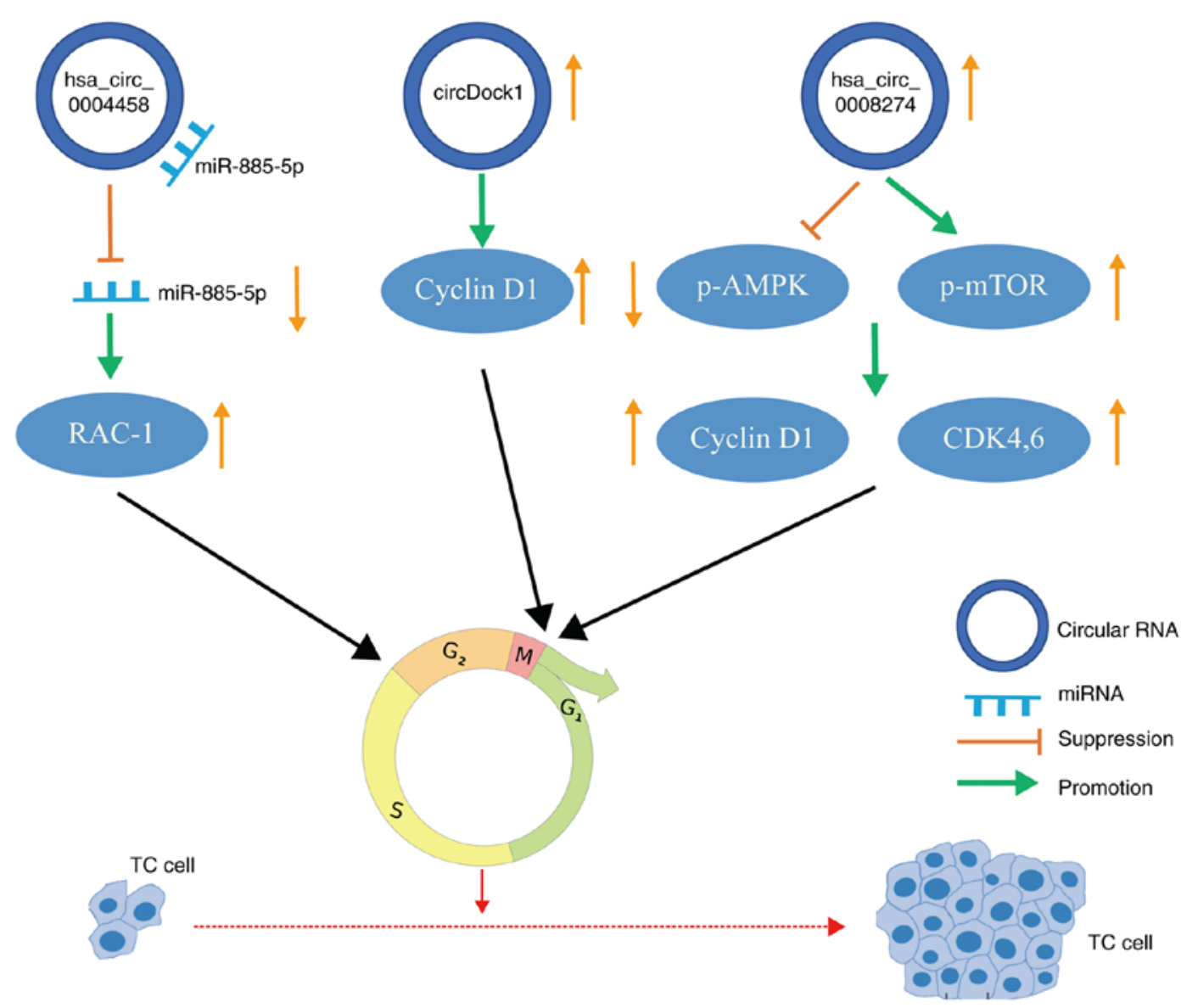

Figure 3. Interrelated regulation of circRNAs and the cell cycle. The biological role of circRNAs in the cell cycle and major interconnected regulatory networks in TC. Several fundamental effectors, including AMPK, cyclin D1, RAC1, CDK4 and CDK6, were identified in this network. The abnormal expression of certain circRNAs results in the bypass of key cellular checkpoints and ultimately neoplastic growth. TC, thyroid cancer; circRNA, circular RNA; p-AMPK, phosphorylated adenosine monophosphate kinase; mTOR, mammalian target of rapamycin; RAC1, RAC family small GTPase 1; CDK, cyclin-dependent kinase.

tumor metastasis may reveal them to be potential targets to inhibit the malignant progression of TC. CircRNA of low-density lipoprotein receptor (circ_LDLR) in PTC tissues was significantly upregulated compared with that in normal tissues and served as an miR-195-5p sponge to upregulate the expression of LDLR mRNA, which led to a decrease in the level of E-cadherin and an increase in the level of Twistl. Twist is able to downregulate epithelial markers such as E-cad and upregulate interstitial cell markers such as vimentin by altering the transcription of EMT-related genes $(80,81)$, which promotes EMT transformation in PTC. In PTC cells with high expression of circ_102002, the expression of E-cadherin was downregulated and the expression of $\mathrm{N}$-cadherin and mesenchymal phenotypic markers was upregulated, while PTC cells with low expression of circ_102002 produced the opposite result (82). CIRS-7 had a similar effect: E-cadherin was downregulated in PTC cells with high expression of CIRS-7, while vimentin levels were significantly increased (83). Similarly, another study suggested that circ_0067934 may promote TC by regulating EMT and PI3K/AKT signaling pathways (84). By sponging downstream targets, circRNAs may promote the invasion and metastasis of TC through their regulatory role in the EMT pathway, but the specific process and downstream pathway are largely elusive and require to be further explored.

Glucose metabolism. The glucose metabolism in tumor cells differs from that in normal cells. Only when oxygen is scarce do normal cells rely on glycolysis rather than oxygen-consuming mitochondrial metabolism to create energy. However, tumor cells prefer to perform glycolysis in the cytosol regardless of whether oxygen is sufficient (85-87). This phenomenon was termed the Warburg effect and describes the ability of tumor cells to generate energy at a rapid rate, accompanied by low efficiency in adenosine triphosphate (ATP) production per molecule of glucose (88). Cancer cells undergo rapid growth and proliferation, and their energy demand may be satisfied via glycolysis. The Warburg effect has been suggested to be associated with the regulation of certain oncogenes and tumor suppressors, such as Akt, PI3K and Ras (89). However, the relationship between circRNAs and glucose metabolism in cancer remains to be fully proven. After circCCDC66 gene knockout, the glucose metabolism of PTC cells was significantly inhibited. Further analysis determined that circCCDC66 is able to act as a sponge for miR-211-5p to promote the expression of pyruvate dehydrogenase kinase 4 , thereby increasing the level of glucose metabolism in PTC cells (90). However, circPUM1 was highly expressed in PTC. After downregulation of circPUM1, the expression of hexokinase 2 was downregulated and glycolysis in PTC was blocked (91). Similar research suggested that hsa_circ_0011290 was significantly upregulated in PTC (92). After specific silencing of hsa_circ_0011290 in cells, the glucose metabolism spectrum indicated that glucose uptake was inhibited, lactic acid production decreased, the 
Table I. CircRNAs in TC.

A, Regulating invasiveness

\begin{tabular}{|c|c|c|c|c|}
\hline CircRNA & Expression level & Mechanism & $\begin{array}{l}\text { Diagnostic and } \\
\text { prognostic value }\end{array}$ & (Refs.) \\
\hline circ_FAT1 & $\begin{array}{l}\text { Upregulated in PTC } \\
\text { cell lines and tissues }\end{array}$ & Sponge miR-873 to regulate ZEB1 & - & (34) \\
\hline circ_102171 & $\begin{array}{l}\text { Upregulated in PTC } \\
\text { tissues and cells }\end{array}$ & $\begin{array}{l}\text { Interacts with CTNNBIP1 to block } \\
\text { its interaction with the } \beta \text {-catenin/TCF3/ } \\
\text { TCF4/LEF1 complex }\end{array}$ & - & (39) \\
\hline circ_BACH2 & $\begin{array}{l}\text { Upregulated in PTC } \\
\text { tissues and cells }\end{array}$ & $\begin{array}{l}\text { Sponges miR-139-5p and relieves } \\
\text { suppression of the target LMO4 }\end{array}$ & AUC was 0.8819 & (61) \\
\hline circ_RASSF2 & $\begin{array}{l}\text { Upregulated in PTC } \\
\text { tissues and cells }\end{array}$ & $\begin{array}{l}\text { Sponges miR-1178; downregulates } \\
\text { TLR4 expression }\end{array}$ & - & $(63)$ \\
\hline circ_0008274 & $\begin{array}{l}\text { Upregulated in PTC } \\
\text { tissues and cells }\end{array}$ & $\begin{array}{l}\text { Modulates AMPK/mTOR signaling } \\
\text { pathway }\end{array}$ & $\begin{array}{l}\text { Associated with TNM } \\
\text { stage and lymph node } \\
\text { metastasis }\end{array}$ & (64) \\
\hline circ_0103552 & $\begin{array}{l}\text { Upregulated in PTC } \\
\text { tissues and cells }\end{array}$ & Sponges miR-127 & - & $(65)$ \\
\hline circ_FOXM1 & $\begin{array}{l}\text { Upregulated in PTC } \\
\text { tissues and cells }\end{array}$ & $\begin{array}{l}\text { Sponges miR-1179; upregulates } \\
\text { HMGB } 1 \text { expression }\end{array}$ & $\begin{array}{l}\text { Associated with tumor } \\
\text { size, tumor stage and } \\
\text { poor lymph node } \\
\text { metastasis }\end{array}$ & (66) \\
\hline hsa_circ_0058124 & $\begin{array}{l}\text { Upregulated in TC } \\
\text { tissues and cells }\end{array}$ & $\begin{array}{l}\text { Sponges miR-940; downregulates } \\
\text { MAPK1 protein levels }\end{array}$ & - & $(67,107)$ \\
\hline circ_FNDC3B & $\begin{array}{l}\text { Upregulated in PTC } \\
\text { tissues and cells }\end{array}$ & $\begin{array}{l}\text { Sponges miR-1178; downregulates } \\
\text { TLR4 expression }\end{array}$ & - & (68) \\
\hline circ_EIF3I & $\begin{array}{l}\text { Upregulated in PTC } \\
\text { tissues }\end{array}$ & $\begin{array}{l}\text { Sponges miR-149; upregulates } \\
\text { KIF2A expression }\end{array}$ & - & (69) \\
\hline circ_RAPGEF5 & $\begin{array}{l}\text { Upregulated in PTC } \\
\text { tissues and cell }\end{array}$ & Sponges miR-198; upregulates FGFR1 & AUC was 0.711 & $(107)$ \\
\hline hsa_circ_0124055 & $\begin{array}{l}\text { Upregulated in TC } \\
\text { tissues }\end{array}$ & - & AUC was 0.836 & (114) \\
\hline hsa_circ_0101622 & Upregulated in TC tissues & - & AUC was 0.805 & $(114)$ \\
\hline circ_ABCB10 & Upregulated in TC tissues & Downregulates KLF6 & - & (59) \\
\hline
\end{tabular}

B, Regulation of the cell cycle

\begin{tabular}{|c|c|c|c|c|}
\hline CircRNA & Expression level & Mechanism & $\begin{array}{l}\text { Diagnostic and } \\
\text { prognostic value }\end{array}$ & (Refs.) \\
\hline circDOCK1 & Upregulated in TC tissues & $\begin{array}{l}\text { Sponges miR-124; dampens } \\
\text { signaling transduction of } \\
\text { JAK/STAT/AMPK }\end{array}$ & - & (71) \\
\hline has_circ_0008274 & Upregulated in PTC tissues & $\begin{array}{l}\text { Inhibits activation of the } \\
\text { AMPK/mTOR signaling pathway }\end{array}$ & $\begin{array}{l}\text { Associated with TNM } \\
\text { stage and lymph node } \\
\text { metastasis }\end{array}$ & (64) \\
\hline hsa_circ_0004458 & $\begin{array}{l}\text { Upregulated in PTC } \\
\text { tissues and cells }\end{array}$ & $\begin{array}{l}\text { Sponges miR-885-5p; activation of } \\
\text { RAC1 }\end{array}$ & - & (73) \\
\hline circ_0001666 & $\begin{array}{l}\text { Upregulated in PTC } \\
\text { tissues and cells }\end{array}$ & $\begin{array}{l}\text { Sponges } \mathrm{miR}-330-5 \mathrm{p} / \\
\mathrm{miR}-193 \mathrm{a}-5 \mathrm{p} / \mathrm{miR}-326\end{array}$ & $\begin{array}{l}\text { Associated with lymph } \\
\text { node metastasis }\end{array}$ & (75) \\
\hline circ_PSD3 & $\begin{array}{l}\text { Upregulated in PTC } \\
\text { tissues }\end{array}$ & $\begin{array}{l}\text { Sponges miR- } 637 \text { to regulate } \\
\text { HEMGN and influence the } \\
\text { PI3K/Akt signaling pathway }\end{array}$ & - & (76) \\
\hline
\end{tabular}


Table I. Continued.

C, Regulation of epithelial-mesenchymal transition

\begin{tabular}{|c|c|c|c|c|}
\hline CircRNA & Expression level & Mechanism & $\begin{array}{l}\text { Diagnostic and } \\
\text { prognostic value }\end{array}$ & (Refs.) \\
\hline circ_102002 & $\begin{array}{l}\text { Upregulated in PTC } \\
\text { tissues and cells }\end{array}$ & Sponges miR-488-3p to regulate HAS2 & - & $(82)$ \\
\hline circ_0067934 & $\begin{array}{l}\text { Upregulated in } \\
\text { TC cells }\end{array}$ & $\begin{array}{l}\text { Sponges miR-1304; upregulated } \\
\text { CXCR } 1 \text { expression }\end{array}$ & $\begin{array}{l}\text { Correlated with AJCC } \\
\text { grade, lymph node } \\
\text { metastasis and survival rate }\end{array}$ & $(84)$ \\
\hline circ_LDLR & $\begin{array}{l}\text { Upregulated in PTC } \\
\text { tissues and cells }\end{array}$ & $\begin{array}{l}\text { Sponges miR-195-5p to regulate } \\
\text { LIPH expression }\end{array}$ & - & $(80)$ \\
\hline CIRS-7 & $\begin{array}{l}\text { Upregulated in PTC } \\
\text { tissues and cells }\end{array}$ & Sponges miR-7 to regulate EGFR & - & $(83)$ \\
\hline \multicolumn{5}{|c|}{ D, Regulation of glucose metabolism } \\
\hline CircRNA & Expression level & Mechanism & $\begin{array}{l}\text { Diagnostic and } \\
\text { prognostic value }\end{array}$ & (Refs.) \\
\hline circCCDC66 & $\begin{array}{l}\text { Upregulated in TC } \\
\text { tissues and cells }\end{array}$ & $\begin{array}{l}\text { Sponges miR-211-5p and } \\
\text { upregulates PDK4 }\end{array}$ & - & $(100)$ \\
\hline hsa_circ_0011290 & $\begin{array}{l}\text { Upregulated in PTC } \\
\text { tissues }\end{array}$ & $\begin{array}{l}\text { Sponges miR-1252; positively } \\
\text { modulates FSTL1 expression }\end{array}$ & - & $(92)$ \\
\hline circPUM1 & $\begin{array}{l}\text { Upregulated in PTC } \\
\text { tissues and cells }\end{array}$ & $\begin{array}{l}\text { Sponges miR-21-5p; downregulates } \\
\text { MAPK1 }\end{array}$ & - & $(91)$ \\
\hline
\end{tabular}

E, Enhancement of cisplatin resistance

\begin{tabular}{|c|c|c|c|c|}
\hline CircRNA & Expression level & Mechanism & $\begin{array}{l}\text { Diagnostic and } \\
\text { prognostic value }\end{array}$ & (Refs.) \\
\hline circEIF6 & $\begin{array}{l}\text { Upregulated in ATC } \\
\text { tissues and cells }\end{array}$ & $\begin{array}{l}\text { Sponges miR-144-3p; increases } \\
\text { TGF- } \alpha \text { expression }\end{array}$ & - & (99) \\
\hline \multicolumn{5}{|l|}{ F, Other } \\
\hline CircRNA & Expression level & Mechanism & $\begin{array}{l}\text { Diagnostic and } \\
\text { prognostic value }\end{array}$ & (Refs.) \\
\hline hsa_circ_0137287 & $\begin{array}{l}\text { Downregulated in PTC } \\
\text { tissues }\end{array}$ & - & $\begin{array}{l}\text { AUC was } 0.8973 \text { for } \\
\text { predicting malignancy; } \\
\text { The AUC was } 0.6885 \text { for } \\
\text { predicting extrathyroidal } \\
\text { extension; the AUC was } \\
0.6691 \text { for predicting } \\
\text { lymph node metastasis }\end{array}$ & (105) \\
\hline hsa_circRNA_007148 & $\begin{array}{l}\text { Upregulated in PTC } \\
\text { tissues }\end{array}$ & - & $\begin{array}{l}\text { AUC was } 0.846 \\
\text { correlated with LNM }\end{array}$ & (106) \\
\hline hsa_circRNA_047771 & $\begin{array}{l}\text { Downregulated in PTC } \\
\text { tissues }\end{array}$ & - & $\begin{array}{l}\text { Associated with } \\
\text { BRAFV } 600 \text { mutation, } \\
\text { lymph node metastasis } \\
\text { and advanced TNM } \\
\text { stage. AUC was } 0.876\end{array}$ & (106) \\
\hline
\end{tabular}

TC, thyroid cancer; PTC, papillary thyroid carcinoma; ATC, anaplastic TC; circRNA, circular RNA; AUC, area under the receiver operating characteristic curve; AJCC, American Joint Committee on Cancer. 


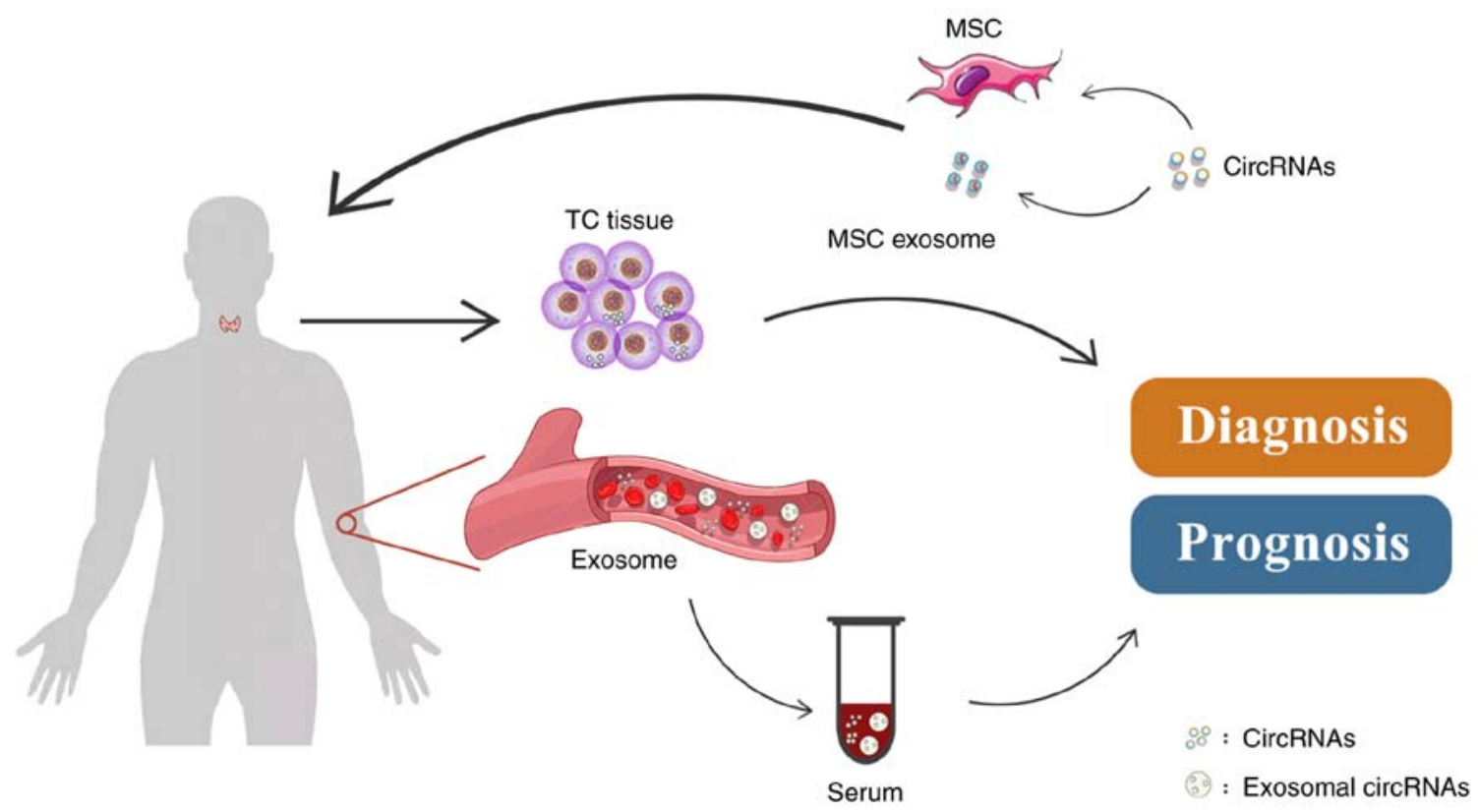

Figure 4. Clinical application of circRNAs. CircRNAs are differentially expressed in TC tissues, serum and plasma exosomes; therefore, they may be used as biomarkers for TC diagnosis and prognosis. MSCs and MSC exosomes may serve as transport vectors for circRNAs and as potential treatments for TC. MSC, mesenchymal stem cell; TC, thyroid cancer; circRNA, circular RNA.

ATP content increased, and cell proliferation and cell viability were significantly inhibited. CircRNAs have a certain effect on glycolysis in TC and may directly or indirectly regulate the activities of key enzymes in glucose metabolism, but their regulatory mode of action remains to be proven.

Drug resistance. Drug resistance refers to the tolerance of microorganisms, parasites and tumor cells to the effect of chemotherapy drugs. Drug resistance may develop prior to treatment or be acquired during treatment by tumors, which is a significant obstacle to overcome in tumor treatment (93). Platinum drugs such as cisplatin are extensively applied in treating human cancers and are considered successful standard therapies (94), but their effect is limited in ATC due to drug resistance (95-98). Liu et al (99) proved that circEIF6 acted as a regulator of drug resistance in ATC. CircEIF6 was upregulated in ATC tissues and cells and controlled transforming growth factor (TGF)- $\alpha$ by sponging miR-144-3p in cells treated with cisplatin. This signaling pathway (circEIF6/miR-144-3p/TGF- $\alpha$ axis) was confirmed to be associated with lowering the sensitivity of ATCs to cisplatin resistance. However, the study did not identify the TGF- $\alpha$ downstream signaling molecules, which requires further research.

In summary, numerous studies suggest that various circRNAs may promote or inhibit the occurrence of TC through different mechanisms (Table I). Most circRNAs function as miRNA sponges and by interacting with RBPs and a single circRNA may participate in different mechanisms of cancer development through sponging a variety of miRNAs. Thus, understanding the regulatory mechanism of circRNAs involved in the TC process may reveal novel therapeutic targets. However, there are limited studies on the subcellular localization and degradation mechanism of circRNAs in TC cells, which may become a novel starting point for research. The current research mainly focused on the regulatory network of circRNAs in PTC, but studies on circRNAs involved in other types and subtypes of TC are scarce, suggesting that other types of TC may become the focus of future research. At the same time, the lack of diversity in experimental models to study the correlation between circRNAs and TC and other uncontrollable factors may also have a negative impact on the repeatability and reliability of the experimental results; thus, unifying the relevant experimental models may lead to more convincing results.

\section{Clinical application prospect}

CircRNAs as biomarkers in cancers. It is universally acknowledged that most cancer types may be cured if diagnosed at an early stage. Due to the high incidence of TC, the demand for early diagnosis is increasing. The features of circRNAs, such as their stability and diverse nature, enable them to accumulate in body fluids and tissues $(12,100,101)$, making it possible for circRNAs to serve as cancer biomarkers. The biomarker value of circRNAs has been proven in different cancer types, such as breast cancer (102), lung cancer (103) and gastric cancer (104). Several circRNAs have been investigated as potential biomarkers through broad clinical sample testing, including tissues, serum and exosomes from patients with TC and healthy controls. These circRNAs have the potential to enable the early diagnosis of TC and predict recurrence and metastasis (Fig. 4).

Diagnostic biomarkers. Recently, through clinicopathologic factor association analysis, Lan et al (105) observed that the downregulation of hsa_circ_0137287 correlated with aggressive clinicopathologic characteristics of PTC, such as lymph node metastasis (LNM), advanced T stage, extrathyroidal extension and larger tumor size. The area under the receiver operating characteristic curve (AUC) was 0.8973, which demonstrated the potential of hsa_circ_0137287 to be a candidate diagnostic biomarker for PTC. Similarly, Ren et al (106) 
identified hundreds of circRNAs upregulated or downregulated separately in PTC tissues. The expression of the most upregulated circRNA, hsa_circRNA_007148, was significantly associated with LNM. In addition, lower expression of hsa_circRNA_047771, which was the most downregulated circRNA, was associated with BRAF ${ }^{\mathrm{V} 600}$ mutation, LNM and advanced TNM stage. The AUC also supported the potential value of hsa_circRNA_047771 and hsa_circRNA_007148 as diagnostic biomarkers for PTC (106). However, due to the invasive and complex nature of detecting circRNAs in tissues, its value in TC diagnosis is limited. In addition, different subtypes of TC probably have different characteristic abnormal circRNAs, which may be the direction of further exploration.

Numerous studies have reported that circRNAs are able to stably accumulate in peripheral blood. Hence, serum circRNAs may be suitable and less invasive biomarkers. A study suggested that two upregulated circRNAs (circRAPGEF5 and hsa_circ_0058124) were stably enriched in the peripheral blood of patients with PTC (107). The results of a further expression analysis of circRAPGEF5 and hsa_circ_0058124 in serum samples during the treatment of patients with PTC indicated that the two circRNAs were markedly decreased along with systematic treatment, indicating that circRNAs may allow researchers to monitor the PTC process dynamically. The AUC for the ability to discriminate PTC from healthy controls was 0.711 for circRAPGEF5 and 0.790 for hsa_circ_0058124. Furthermore, the combination of the two circRNAs (circRAPGEF5 and hsa_circ_0058124) demonstrated a better diagnostic ability than a single circRNA in PTC identification, with an AUC value of 0.860. Therefore, the appropriate selection of a group of several circRNAs may be a novel diagnostic approach that may increase the sensitivity, specificity and accuracy of TC diagnosis and prognosis.

Exosomes are small vesicles with a single membrane, exhibiting the same topology as cells, and their diameter varies from 30 to $200 \mathrm{~nm}$. Select proteins, lipids, nucleic acids and glycoconjugates may be packaged in exosomes (108). Several studies have proven that exosomes may act as carriers of circRNAs and transfer them between cancer cells (109), suggesting that circRNAs in exosomes have the potential to act as biomarkers. Wu et al (63) isolated serum exosomes from 60 serum samples collected from patients with PTC and healthy subjects and indicated that circRASSF2 was overexpressed in serum exosomes from patients with PTC. Logistic regression analysis demonstrated that upregulation of circRASSF2 was markedly associated with tumor stage and LNM. In addition, another study using high-throughput sequencing determined that circRNAs were differentially expressed in serum-derived exosomes collected from patients with PTC and patients with benign thyroid goiter. A total of three upregulated circRNAs and 19 downregulated circRNAs were detected in the former (110). However, no clinicopathologic factor association analysis was performed in that study.

Prognostic biomarkers. Prognosis is a prediction of the course and outcome of a disease. Prognostic evaluation in the early stage of a disease helps mitigate the effects of negative predictive factors. In addition, cancer patients heavily rely on prognostic evaluation to determine their life expectancy. The prognostic value of circRNAs has been proven in diverse cancer types, such as colon cancer (111), lung cancer (112) and triple-negative breast cancer (113). Sun et al (114) indicated that hsa_circ_0124055 and hsa_circ_0101622 were overexpressed in the plasma of patients with TC, which was significantly associated with larger tumor size, poorer TNM stage or histological grade and LNM. Compared with the levels in plasma of patients prior to tumorectomy, hsa_circ_0124055 and hsa_circ_0101622 were markedly decreased after surgery. The patients with high hsa_circ_0124055 or hsa_circ_0101622 expression exhibited shorter overall survival. The AUCs were 0.836 for hsa_circ_0124055 and 0.805 for hsa_circ_0101622, which indicated their TC diagnostic significance. Furthermore, the AUC rose to 0.911 after combining hsa_circ_0124055 with hsa_circ_0101622. In addition, in patients with PTC, circFNDC3B was demonstrated to be upregulated in serum exosomes and tissues. The AUC for circFNDC3B was 0.891 . Patients with PTC with low expression of circFNDC3B exhibited longer overall survival than those with high expression of circFNDC3B according to Kaplan-Meier survival curve analysis (68). Guo et al (22) discovered 8 circRNAs expressed abnormally in PTC tissues, 5 of which were associated with BRAFV600E, capsular invasion, advanced pT stage and LNM. These circRNAs, whose expression levels were associated with the overall survival of patients, may be potential prognostic biomarkers. However, to date, compared to the value reported for circRNA as diagnostic biomarkers, the value of prognostic circRNA biomarkers has not been widely demonstrated.

Potential intervention by mesenchymal stem cells. CircRNAs have attracted increasing attention in the field of tumor research and have potential for interventional, expression or regulatory therapy. There are certain problems associated with circRNAs due to their low targeting, potential off-target effects and biodegradation in vivo. Therefore, novel strategies to improve their regulatory effect and targeting of circRNAs require to be developed. The application of mesenchymal stem cell (MSC) therapy in the field of cancer has attracted increasing attention due to its unique chemotaxis, which brings hope to improve the accuracy of targeted therapy. In addition, exosomes secreted by MSCs are considered promising by researchers due to their special biological characteristics and superiority over MSCs. MSCs are multipotent stem cells with significant potential for regenerative medicine. The therapeutic potential of MSCs may be attributed to the key mechanism of homing, i.e. they are able to migrate to the injured site and differentiate into local components there (115-117).

There are numerous high-quality reviews $(118,119)$ in the literature addressing the basic concept that MSCs have a good targeting transport effect and may thus be used as carriers to target the tumor growth site to exert effective clinical functions. The characteristics of MSCs suggest that they are able to transport therapeutic anticancer genes, making them a unique and promising choice for cancer treatment; part of their recently recognized functions have a wide variety of potential applications. The most important factors of tumorigenesis are epigenetic changes and genetic mutations in proto-oncogenes and tumor suppressor genes (117). Due to the unique characteristics of MSCs, TC may be treated by loading tumor suppressor genes or circRNAs into MSCs. The use of genetically engineered MSCs for gene-directed enzyme/prodrug therapy is a promising therapeutic approach. Kalimuthu et al (120) attempted to develop therapeutic MSCs containing an inducible suicide gene and confirmed its therapeutic 
efficiency for ATC therapy. However, research on the use of MSCs as carriers loaded with circRNAs to treat TC is still in its infancy. In the future, more in-depth research in this area may be performed to provide novel approaches for tumor treatment.

Potential intervention by MSC-derived exosomes. Exosomes are small, lipid-membrane extracellular vesicles (EVs) that are formed by endocytosis, integration and efflux; they have a diameter of 30-150 nm, are stable in a variety of biological fluids, such as urine, plasma and serum (121), and may be used as drug or gene carriers. Therefore, to a certain extent, exosomes derived from MSCs may be a good and promising cargo-loading carrier for the treatment of tumors. Various studies have emphasized the function of miRNAs in TC. However, research concerning the influence of exosomal miRNAs on TC remains limited. Tang et al (122) aimed to uncover the regulatory effects of exosomal miR152 on TC and the underlying mechanisms. They isolated exosomal miR-152 from bone marrow mesenchymal stem cells (BMSCs) and cocultured it with TC cells to explore its potential for therapy. The results indicated that BMSC-derived exosomal miR-152 inhibited the proliferation, invasion and migration of TC cells and promoted cell apoptosis. The therapeutic potential of MSC-derived exosomes has been proven in non-small cell lung carcinoma (123), ischemic muscle injury (124) and liver fibrosis (125). However, the use of exosome-loaded circRNAs in TC has remained unexplored, to the best of our knowledge, suggesting that future studies may further explore related treatments for TC using similar strategies.

Taken together, the application of exosomes for the treatment of tumors is currently a major research hotspot and the utility of exosomes as carriers has also been widely and deeply discussed in the field of cancer. At present, diverse technologies may be used to isolate and analyze EVs, such as density gradient zone centrifugation (119), immunocapture by magnetic beads (126), exosome precipitation or chromatography (127). However, emptying native contents and loading the desired cargos may represent limitations in EV applications. Whether the biological efficacy of exosomes is only related to the cargo loaded into them or whether the effects of exosomes themselves on the delivery of goods have a role, as well as their molecular mechanisms, requires to be further studied. Exosomes are vesicles that mediate cellular communication via paracrine signaling (128); thus, whether the genes loaded into exosomes, such as circRNAs and miRNAs, are able to mediate intercellular communication and the underlying mechanisms of their mode of action require to be investigated.

\section{Future directions and conclusion}

CircRNAs are closed circular noncoding RNAs formed by reverse splicing of precursor RNAs. In recent years, circRNAs have received increasing attention in cancer research. The present study reviewed the role of circRNAs in TC, with an emphasis on their ability to promote and inhibit proliferation, invasion and metastasis of TC cells. CircRNAs affect tumor cells in different ways, such as through regulating the cell cycle, EMT and drug resistance. Of note, the mechanism by which circRNAs regulate glucose metabolism in TC has also been indicated to have an important role. At present, the clinical application of circRNAs is mainly focused on diagnostic and prognostic biomarkers.
CircRNAs have been widely studied as diagnostic and prognostic biomarkers. For the prognosis of patients with TC, regular detection of the expression level of specific circRNAs may bring new improvements to prognosis. In the present review, the possibility of using exosomes from MSCs and MSCs themselves as carriers to load circRNAs for treatment was described. At present, research on the biomarker function of circRNAs in TC is mainly focused on invasive TC tissue biopsy. Attention should be paid to noninvasive body fluids to improve their practicability as diagnostic and prognostic markers. In addition, the immunomodulatory effects of circRNAs in the TC tumor microenvironment, their effects on angiogenesis of TC cells and radiotherapy resistance have not been previously reported, which may become potential research directions in the future. In addition, the downstream signals of certain differentially expressed circRNAs in thyroid carcinoma have not been fully studied and the regulatory circRNA-miRNA-mRNA network mechanism and its effects on the tumor microenvironment, extracellular matrix and cellular communication require to be further studied. CircRNAs may become a novel research direction and may provide therapeutic targets. To date, studies have focused on the discovery signaling pathways of circRNAs acting as miRNA sponges in PTC. However, studies on other aspects, such as circRNAs affecting gene expression and directly affecting proteins, their role as a transcriptional template and the function of circRNAs in other types of TC are currently scarce. In general, circRNAs have great application prospects in the clinical treatment of tumors and the molecular mechanisms of their effect on tumor cells require further experimental research.

\section{Acknowledgements}

Not applicable.

\section{Funding}

The study was supported by the Project of Local Science and Technology Development guided by the Central Government (Innovative Platform for Improving the Ability of Prevention and Treatment of Multiple Diseases in Gansu), the Construction Plan of Gansu Endocrine Disease Clinical Medical Research Center (grant no. 20JR10FA667), the Project of Gansu Natural Science Foundation (grant no. 20JR10RA681), Lanzhou Science and Technology Development Guiding Plan Project (grant no. 2019-ZD-38), College Students' Innovation, Entrepreneurship and Excellence Program of Lanzhou University in 2020 (grant no. 20200060103) and the College Students' Innovation and Entrepreneurship in Lanzhou University in 2021 (grant no. 20210060155).

\section{Availability of data and materials}

Data sharing is not applicable to this article, as no datasets were generated or analyzed during the current study.

\section{Authors' contributions}

GZ and XC contributed to the literature search and wrote the original draft of the manuscript. YK and XZ contributed to the revised version of the manuscript. XT and CM generated all the figures. SF contributed by performing the conceptualization. 
All authors read and approved the final manuscript. Data authentication is not applicable.

\section{Ethics approval and consent to participate}

Not applicable.

\section{Patient consent for publication}

Not applicable.

\section{Competing interests}

The authors declare that they have no competing interests.

\section{References}

1. Prete A, Borges de Souza P, Censi S, Muzza M, Nucci N and Sponziello M: Update on fundamental mechanisms of thyroid cancer. Front Endocrinol (Lausanne) 11: 102, 2020.

2. Kitahara CM and Sosa JA: The changing incidence of thyroid cancer. Nat Rev Endocrinol 12: 646-653, 2016.

3. Miller KD, Fidler-Benaoudia M, Keegan TH, Hipp HS, Jemal A and Siegel RL: Cancer statistics for adolescents and young adults, 2020. CA Cancer J Clin 70: 443-459, 2020.

4. ASCO: Thyroid cancer: Statistics. https://www.cancer.net/cancertypes/thyroid-cancer/statistics. Accessed May 5, 2021.

5. Massimino M, Evans DB, Podda M, Spinelli C, Collini P, Pizzi N and Bleyer A: Thyroid cancer in adolescents and young adults Pediatr Blood Cancer 65: e27025, 2018.

6. Fleeman N, Houten R, Bagust A, Richardson M, Beale S, Boland A, Dundar Y, Greenhalgh J, Hounsome J, Duarte R and Shenoy A: Lenvatinib and sorafenib for differentiated thyroid cancer after radioactive iodine: A systematic review and economic evaluation. Health Technol Assess 24: 1-180, 2020

7. Molinaro E, Romei C, Biagini A, Sabini E, Agate L, Mazzeo S, Materazzi G, Sellari-Franceschini S, Ribechini A, Torregrossa L, et al: Anaplastic thyroid carcinoma: From clinicopathology to genetics and advanced therapies. Nat Rev Endocrinol 13: 644-660, 2017

8. Ahn HS, Kim HJ and Welch HG: Korea's thyroid-cancer 'epidemic'-screening and overdiagnosis. N Engl J Med 371: 1765-1767, 2014.

9. Ashwal-Fluss R, Meyer M, Pamudurti NR, Ivanov A, Bartok O, Hanan M, Evantal N, Memczak S, Rajewsky N and Kadener S: circRNA biogenesis competes with pre-mRNA splicing. Mol Cell 56: 55-66, 2014.

10. Guo JU, Agarwal V, Guo H and Bartel DP: Expanded identification and characterization of mammalian circular RNAs. Genome Biol 15: 409, 2014.

11. Lasda E and Parker R: Circular RNAs: Diversity of form and function. RNA 20: 1829-1842, 2014.

12. Jeck WR, Sorrentino JA, Wang K, Slevin MK, Burd CE, Liu J, Marzluff WF and Sharpless NE: Circular RNAs are abundant, conserved, and associated with ALU repeats. RNA 19: 141-157, 2013.

13. Suzuki H, Zuo Y, Wang J, Zhang MQ, Malhotra A and Mayeda A: Characterization of RNase R-digested cellular RNA source that consists of lariat and circular RNAs from pre-mRNA splicing. Nucleic Acids Res 34: e63, 2006

14. Enuka Y, Lauriola M, Feldman ME, Sas-Chen A, Ulitsky I and Yarden Y: Circular RNAs are long-lived and display only minimal early alterations in response to a growth factor. Nucleic Acids Res 44: 1370-1383, 2016.

15. Rybak-Wolf A, Stottmeister C, Glažar P, Jens M, Pino N, Giusti S, Hanan M, Behm M, Bartok O, Ashwal-Fluss R, et al: Circular RNAs in the mammalian brain are highly abundant, conserved, and dynamically expressed. Mol Cell 58: 870-885, 2015.

16. Su H, Lin F, Deng X, Shen L, Fang Y, Fei Z, Zhao L, Zhang X, Pan H, Xie D, et al: Profiling and bioinformatics analyses revea differential circular RNA expression in radioresistant esophageal cancer cells. J Transl Med 14: 225, 2016.

17. Zhang $\mathrm{M}$ and $\mathrm{Du} \mathrm{X}$ : Noncoding RNAs in gastric cancer: Research progress and prospects. World J Gastroenterol 22: 6610-6618,2016
18. Xiong W, Ai YQ, Li YF, Ye Q, Chen ZT, Qin JY, Liu QY, Wang H, $\mathrm{Ju}$ YH, Li WH and Li YF: Microarray analysis of circular RNA expression profile associated with 5-fluorouracil-based chemoradiation resistance in colorectal cancer cells. Biomed Res Int 2017: 8421614, 2017.

19. Yao T, Chen Q, Fu L and Guo J: Circular RNAs: Biogenesis, properties, roles, and their relationships with liver diseases. Hepatol Res 47: 497-504, 2017.

20. Zheng J, Liu X, Xue Y, Gong W, Ma J, Xi Z, Que Z and Liu Y: TTBK2 circular RNA promotes glioma malignancy by regulating miR-217/HNF1ß/Derlin-1 pathway. J Hematol Oncol 10: 52, 2017.

21. Zhong Z, Lv M and Chen J: Screening differential circular RNA expression profiles reveals the regulatory role of circTCF25-miR-103a-3p/miR-107-CDK6 pathway in bladder carcinoma. Sci Rep 6: 30919, 2016.

22. Guo D, Li F, Zhao X, Long B, Zhang S, Wang A, Cao D, Sun J and Li B: Circular RNA expression and association with the clinicopathological characteristics in papillary thyroid carcinoma. Oncol Rep 44: 519-532, 2020.

23. Bartel DP: MicroRNAs: Genomics, biogenesis, mechanism, and function. Cell 116: 281-297, 2004.

24. Lewis BP, Shih IH, Jones-Rhoades MW, Bartel DP and Burge CB: Prediction of mammalian microRNA targets. Cell 115: 787-798, 2003.

25. Zhou X and Yang PC: MicroRNA: A small molecule with a big biological impact. Microrna 1: 1, 2012.

26. Lee KP, Shin YJ, Panda AC, Abdelmohsen K, Kim JY, Lee SM, Bahn YJ, Choi JY, Kwon ES, Baek SJ, et al: miR-431 promotes differentiation and regeneration of old skeletal muscle by targeting Smad4. Genes Dev 29: 1605-1617, 2015.

27. Panda AC, Abdelmohsen K and Gorospe M: SASP regulation by noncoding RNA. Mech Ageing Dev 168: 37-43, 2017.

28. Panda AC, Sahu I, Kulkarni SD, Martindale JL, Abdelmohsen K, Vindu A, Joseph J, Gorospe M and Seshadri V: miR-196b-mediated translation regulation of mouse insulin2 via the 5'UTR. PLoS One 9: e101084, 2014.

29. Munk R, Panda AC, Grammatikakis I, Gorospe M and Abdelmohsen K: Senescence-associated MicroRNAs. Int Rev Cell Mol Biol 334: 177-205, 2017.

30. Hansen TB, Jensen TI, Clausen BH, Bramsen JB, Finsen B, Damgaard CK and Kjems J: Natural RNA circles function as efficient microRNA sponges. Nature 495: 384-388, 2013.

31. Memczak S, Jens M, Elefsinioti A, Torti F, Krueger J, Rybak A, Maier L, Mackowiak SD, Gregersen LH, Munschauer M, et al: Circular RNAs are a large class of animal RNAs with regulatory potency. Nature 495: 333-338, 2013.

32. Pan H, Li T, Jiang Y, Pan C, Ding Y, Huang Z, Yu H and Kong D: Overexpression of sircular RNA ciRS-7 abrogates the tumor suppressive effect of miR-7 on gastric cancer via PTEN/PI3K/AKT signaling pathway. J Cell Biochem 119: 440-446, 2018

33. Yu L, Gong X, Sun L, Zhou Q, Lu B and Zhu L: The circular RNA cdrlas act as an oncogene in hepatocellular carcinoma through targeting miR-7 expression. PLoS One 11: e0158347, 2016.

34. Liu J, Li H, Wei C, Ding J, Lu J, Pan G and Mao A: circFAT1(e2) promotes papillary thyroid cancer proliferation, migration, and invasion via the miRNA-873/ZEB1 axis. Comput Math Methods Med 2020: 1459368, 2020.

35. Conlon EG and Manley JL: RNA-binding proteins in neurodegeneration: Mechanisms in aggregate. Genes Dev 31: 1509-1528, 2017.

36. Errichelli L, Dini Modigliani S, Laneve P, Colantoni A, Legnini I, Capauto D, Rosa A, De Santis R, Scarfò R, Peruzzi G, et al: FUS affects circular RNA expression in murine embryonic stem cell-derived motor neurons. Nat Commun 8: 14741, 2017.

37. Yang Q, Du WW, Wu N, Yang W, Awan FM, Fang L, Ma J, Li X, Zeng Y, Yang Z, et al: A circular RNA promotes tumorigenesis by inducing c-myc nuclear translocation. Cell Death Differ 24: 1609-1620, 2017

38. Yang ZG, Awan FM, Du WW, Zeng Y, Lyu J, Wu D, Gupta S, Yang W and Yang BB: The circular RNA interacts with STAT3, increasing its nuclear translocation and wound repair by modulating Dnmt3a and miR-17 function. Mol Ther 25: 2062-2074, 2017.

39. Bi W, Huang J, Nie C, Liu B, He G, Han J, Pang R, Ding Z, Xu J and Zhang J: CircRNA circRNA_102171 promotes papillary thyroid cancer progression through modulating CTNNBIP1-dependent activation of $\beta$-catenin pathway. J Exp Clin Cancer Res 37: 275, 2018.

40. Du WW, Yang W, Chen Y, Wu ZK, Foster FS, Yang Z, Li X and Yang BB: Foxo3 circular RNA promotes cardiac senescence by modulating multiple factors associated with stress and senescence responses. Eur Heart J 38: 1402-1412, 2017. 
41. Feng Y, Yang Y, Zhao X, Fan Y, Zhou L, Rong J and Yu Y: Circular RNA circ0005276 promotes the proliferation and migration of prostate cancer cells by interacting with FUS to transcriptionally activate XIAP. Cell Death Dis 10: 792, 2019.

42. Garikipati VNS, Verma SK, Cheng Z, Liang D, Truongcao MM, Cimini M, Yue Y, Huang G, Wang C, Benedict C, et al: Circular RNA CircFndc3b modulates cardiac repair after myocardial infarction via FUS/VEGF-A axis. Nat Commun 10: 4317, 2019.

43. Li Z, Huang C, Bao C, Chen L, Lin M, Wang X, Zhong G, Yu B, $\mathrm{Hu}$ W, Dai L, et al: Exon-intron circular RNAs regulate transcription in the nucleus. Nat Struct Mol Biol 22: 256-264, 2015.

44. Zhang Y, Zhang XO, Chen T, Xiang JF, Yin QF, Xing YH, Zhu S, Yang L and Chen LL: Circular intronic long noncoding RNAs. Mol Cell 51: 792-806, 2013.

45. Wu N, Yuan Z, Du KY, Fang L, Lyu J, Zhang C, He A, Eshaghi E, Zeng K, Ma J, et al: Translation of yes-associated protein (YAP) was antagonized by its circular RNA via suppressing the assembly of the translation initiation machinery. Cell Death Differ 26: 2758-2773, 2019

46. Chen N, Zhao G, Yan X, Lv Z, Yin H, Zhang S, Song W, Li X, Li L, Du Z, et al: A novel FLI1 exonic circular RNA promotes metastasis in breast cancer by coordinately regulating TET1 and DNMT1. Genome Biol 19: 218, 2018.

47. Legnini I, Di Timoteo G, Rossi F, Morlando M, Briganti F, Sthandier O, Fatica A, Santini T, Andronache A, Wade M, et al: Circ-ZNF609 is a circular RNA that can be translated and functions in myogenesis. Mol Cell 66: 22-37.e29, 2017.

48. Stagsted LV, Nielsen KM, Daugaard I and Hansen TB: Noncoding AUG circRNAs constitute an abundant and conserved subclass of circles. Life Sci Alliance 2: e201900398, 2019.

49. Wawrzyniak O,Zarębska Ż, Kuczyński K, Gotz-Więckowska A and Rolle K: Protein-related circular RNAs in human pathologies. Cells 9: 1841, 2020.

50. Pamudurti NR, Bartok O, Jens M, Ashwal-Fluss R, Stottmeister C, Ruhe L, Hanan M, Wyler E, Perez-Hernandez D, Ramberger E, et al: Translation of circRNAs. Mol Cell 66: 9-21.e27, 2017.

51. Meyer KD, Patil DP, Zhou J, Zinoviev A, Skabkin MA Elemento O, Pestova TV, Qian SB and Jaffrey SR: 5' UTR m(6)a promotes cap-independent translation. Cell 163: 999-1010, 2015.

52. Yang Y, Fan X, Mao M, Song X, Wu P, Zhang Y, Jin Y, Yang Y, Chen LL, Wang Y, et al: Extensive translation of circular RNAs driven by N(6)-methyladenosine. Cell Res 27: 626-641, 2017.

53. Abe N, Matsumoto K, Nishihara M, Nakano Y, Shibata A, Maruyama H, Shuto S, Matsuda A, Yoshida M, Ito Y and Abe H: Rolling circle translation of circular RNA in living human cells. Sci Rep 5: 16435, 2015.

54. Liang ZX, Liu HS, Xiong L, Yang X, Wang FW, Zeng ZW, He XW, Wu XR and Lan P: A novel NF- $\mathrm{B}$ regulator encoded by circPLCE1 inhibits colorectal carcinoma progression by promoting RPS3 ubiquitin-dependent degradation. Mol Cancer 20: 103, 2021

55. Lei M, Zheng G, Ning Q, Zheng J and Dong D: Translation and functional roles of circular RNAs in human cancer. Mol Cancer 19: 30, 2020

56. Huang C, Liang D, Tatomer DC and Wilusz JE: A length-dependent evolutionarily conserved pathway controls nuclear export of circular RNAs. Genes Dev 32: 639-644, 2018.

57. Natua S, Dhamdhere SG, Mutnuru SA and Shukla S: Interplay within tumor microenvironment orchestrates neoplastic RNA metabolism and transcriptome diversity. Wiley Interdiscip Rev RNA 9: e1676, 2021

58. Viralippurath Ashraf J, Sasidharan Nair V, Saleh R and Elkord E: Role of circular RNAs in colorectal tumor microenvironment. Biomed Pharmacother 137: 111351, 2021.

59. Han XT, Jiang JQ, Li MZ and Cong QM: Circular RNA circ-ABCB10 promotes the proliferation and invasion of thyroid cancer by targeting KLF6. Eur Rev Med Pharmacol Sci 24: 9774 , 2020.

60. DiFeo A, Martignetti JA and Narla G: The role of KLF6 and its splice variants in cancer therapy. Drug Resist Updat 12: 1-7, 2009.

61. Cai X, Zhao Z, Dong J, Lv Q, Yun B, Liu J, Shen Y, Kang J and Li J: Circular RNA circBACH2 plays a role in papillary thyroid carcinoma by sponging miR-139-5p and regulating LMO4 expression. Cell Death Dis 10: 184, 2019.

62. Racevskis J, Dill A, Sparano JA and Ruan H: Molecular cloning of LMO41, a new human LIM domain gene. Biochim Biophys Acta 1445: 148-153, 1999.

63. Wu G, Zhou W, Lin X, Sun Y, Li J, Xu H, Shi P, Gao L and Tian X: circRASSF2 acts as ceRNA and promotes papillary thyroid carcinoma progression through miR-1178/TLR4 signaling pathway. Mol Ther Nucleic Acids 19: 1153-1163, 2020.
64. Zhou GK, Zhang GY, Yuan ZN, Pei R and Liu DM: Has circ_0008274 promotes cell proliferation and invasion involving AMPK/mTOR signaling pathway in papillary thyroid carcinoma. Eur Rev Med Pharmacol Sci 22: 8772-8780, 2018.

65. Zheng FB, Chen D, Ding YY, Wang SR, Shi DD and Zhu ZP Circular RNA circ 0103552 promotes the invasion and migration of thyroid carcinoma cells by sponging miR-127. Eur Rev Med Pharmacol Sci 24: 2572-2578, 2020.

66. Ye M, Hou H, Shen M, Dong S and Zhang T: Circular RNA circFOXM1 plays a role in papillary thyroid carcinoma by sponging miR-1179 and regulating HMGB1 expression. Mol Ther Nucleic Acids 19: 741-750, 2020.

67. Yao Y, Chen X, Yang H, Chen W, Qian Y, Yan Z, Liao T, Yao W, Wu W, Yu T, et al: Hsa_circ_0058124 promotes papillary thyroid cancer tumorigenesis and invasiveness through the NOTCH3/GATAD2A axis. J Exp Clin Cancer Res 38: 318, 2019.

68. Wu G, Zhou W, Pan X, Sun Z, Sun Y, Xu H, Shi P, Li J, Gao L and Tian X: Circular RNA profiling reveals exosomal circ 0006156 as a novel biomarker in papillary thyroid cancer. Mol Ther Nucleic Acids 19: 1134-1144, 2020.

69. Wang YF, Li MY, Tang YF, Jia M, Liu Z and Li HQ: Circular RNA circEIF3I promotes papillary thyroid carcinoma progression through competitively binding to miR-149 and upregulating KIF2A expression. Am J Cancer Res 10: 1130-1139, 2020.

70. Qie S and Diehl JA: Cyclin D1, cancer progression, and opportunities in cancer treatment. J Mol Med (Berl) 94: 1313-1326, 2016.

71. Cui W and Xue J: Circular RNA DOCK1 downregulates microRNA-124 to induce the growth of human thyroid cancer cell lines. Biofactors 46: 591-599, 2020.

72. Motoshima H, Goldstein BJ, Igata M and Araki E: AMPK and cell proliferation-AMPK as a therapeutic target for atherosclerosis and cancer. J Physiol 574: 63-71, 2006.

73. Jin X, Wang Z, Pang W, Zhou J, Liang Y, Yang J, Yang L and Zhang Q: Upregulated hsa_circ_0004458 contributes to progression of papillary thyroid carcinoma by inhibition of miR-885-5p and activation of RAC1. Med Sci Monit 24: 5488-5500, 2018

74. Yan Y, Greer PM, Cao PT, Kolb RH and Cowan KH: RAC1 GTPase plays an important role in $\gamma$-irradiation induced G2/M checkpoint activation. Breast Cancer Res 14: R60, 2012.

75. Qi Y, He J, Zhang Y, Wang L, Yu Y, Yao B and Tian Z: Circular RNA hsa_circ_0001666 sponges miR_x001E_330_x001E_5p, miR_x001E_193a_x001E_5p and miR_x001E_326, and promotes papillary thyroid carcinoma progression via upregulation of ETV4. Oncol Rep 45: 50, 2021.

76. Li Z, Huang X, Liu A, Xu J, Lai J, Guan H and Ma J: Circ_PSD3 promotes the progression of papillary thyroid carcinoma via the miR-637/HEMGN axis. Life Sci 264: 118622, 2021.

77. Feldkoren B, Hutchinson R, Rapoport Y, Mahajan A and Margulis V: Integrin signaling potentiates transforming growth factor-beta 1 (TGF- $\beta 1$ ) dependent down-regulation of E-Cadherin expression-important implications for epithelial to mesenchymal transition (EMT) in renal cell carcinoma. Exp Cell Res 355: 57-66, 2017.

78. Nishiyama M, Tsunedomi R, Yoshimura K, Hashimoto N, Matsukuma S, Ogihara H, Kanekiyo S, Iida M, Sakamoto K, Suzuki N, et al: Metastatic ability and the epithelial-mesenchymal transition in induced cancer stem-like hepatoma cells. Cancer Sci 109: 1101-1109, 2018.

79. Derynck R and Weinberg RA: EMT and cancer: More than meets the eye. Dev Cell 49: 313-316, 2019.

80. Gui X, Li Y, Zhang X, Su K and Cao W: Circ_LDLR promoted the development of papillary thyroid carcinoma via regulating miR-195-5p/LIPH axis. Cancer Cell Int 20: 241, 2020

81. Shibue T and Weinberg RA: EMT, CSCs, and drug resistance: The mechanistic link and clinical implications. Nat Rev Clin Oncol 14: 611-629, 2017.

82. Zhang W, Liu T, Li T and Zhao X: Hsa_circRNA_102002 facilitates metastasis of papillary thyroid cancer through regulating miR-488-3p/HAS2 axis. Cancer Gene Ther 28: 279-293, 2021.

83. Han JY, Guo S, Wei N, Xue R, Li W, Dong G, Li J, Tian X, Chen C, Qiu S, et al: ciRS-7 promotes the proliferation and migration of papillary thyroid cancer by negatively regulating the miR-7/Epidermal growth factor receptor axis. Biomed Res Int 2020: 9875636, 2020.

84. Wang H, Yan X, Zhang H and Zhan X: CircRNA circ 0067934 overexpression correlates with poor prognosis and promotes thyroid carcinoma progression. Med Sci Monit 25: 1342-1349, 2019.

85. Warburg O, Wind $\mathrm{F}$ and Negelein E: The metabolism of tumors in the body. J Gen Physiol 8: 519-530, 1927. 
86. Warburg O: On the origin of cancer cells. Science 123: 309-314 1956.

87. Warburg O: On respiratory impairment in cancer cells. Science 124: 269-270, 1956.

88. Lunt SY and Vander Heiden MG: Aerobic glycolysis: Meeting the metabolic requirements of cell proliferation. Annu Rev Cell Dev Biol 27: 441-464, 2011.

89. Dang CV, Hamaker M, Sun P, Le A and Gao P: Therapeutic targeting of cancer cell metabolism. J Mol Med (Berl) 89 205-212, 2011

90. Ren H, Song Z, Chao $\mathrm{C}$ and Mao W: circCCDC66 promotes thyroid cancer cell proliferation, migratory and invasive abilities and glycolysis through the miR-211-5p/PDK4 axis. Oncol Lett 21: 416, 2021

91. Li Y, Qin J, He Z, Cui G, Zhang K and Wu B: Knockdown of circPUM1 impedes cell growth, metastasis and glycolysis of papillary thyroid cancer via enhancing MAPK1 expression by serving as the sponge of miR-21-5p. Genes Genomics 43 : $141-150,2021$.

92.Hu Z, Zhao P, Zhang K, Zang L, Liao H and Ma W: Hsa circ_0011290 regulates proliferation, apoptosis and glycolytic phenotype in papillary thyroid cancer via miR-1252/FSTL1 signal pathway. Arch Biochem Biophys 685: 108353, 2020

93. Longley DB and Johnston PG: Molecular mechanisms of drug resistance. J Pathol 205: 275-292, 2005.

94. Shaili E: Platinum anticancer drugs and photochemotherapeutic agents: Recent advances and future developments. Sci Prog 97: $20-40,2014$

95. Hundahl SA, Fleming ID, Fremgen AM and Menck HR: A national cancer data base report on 53,856 cases of thyroid carcinoma treated in the U.S., 1985-1995 [see commetns] Cancer 83: 2638-2648, 1998.

96. Kitamura Y, Shimizu K, Nagahama M, Sugino K, Ozaki O, Mimura T, Ito K, Ito K and Tanaka S: Immediate causes of death in thyroid carcinoma: Clinicopathological analysis of 161 fatal cases. J Clin Endocrinol Metab 84: 4043-4049, 1999.

97. Antonelli A, Miccoli P, Derzhitski VE, Panasiuk G, Solovieva N and Baschieri L: Epidemiologic and clinical evaluation of thyroid cancer in children from the Gomel region (Belarus) World J Surg 20: 867-871, 1996.

98. Zheng X, Cui D, Xu S, Brabant G and Derwahl M: Doxorubicin fails to eradicate cancer stem cells derived from anaplastic thyroid carcinoma cells: Characterization of resistant cells. Int J Oncol 37: 307-315, 2010.

99. Liu F, Zhang J, Qin L, Yang Z, Xiong J, Zhang Y, Li R, Li S, Wang H, Yu B, et al: Circular RNA EIF6 (Hsa_circ_0060060) sponges miR-144-3p to promote the cisplatin-resistance of human thyroid carcinoma cells by autophagy regulation. Aging (Albany NY) 10: 3806-3820, 2018.

100. Salzman J, Chen RE, Olsen MN, Wang PL and Brown PO: Cell-type specific features of circular RNA expression. PLoS Genet 9: e1003777, 2013

101. Memczak S, Papavasileiou P, Peters O and Rajewsky N Identification and characterization of circular RNAs as a new class of putative biomarkers in human blood. PLoS One 10 e0141214, 2015.

102. Yin WB, Yan MG, Fang X, Guo JJ, Xiong W and Zhang RP: Circulating circular RNA hsa_circ_0001785 acts as a diagnostic biomarker for breast cancer detection. Clin Chim Acta 487: 363-368, 2018

103. Chen Y, Wei S, Wang X, Zhu X and Han S: Progress in research on the role of circular RNAs in lung cancer. World J Surg Oncol 16: 215, 2018

104. Wei J, Wei W, Xu H, Wang Z, Gao W, Wang T, Zheng Q, Shu Y and De W: Circular RNA hsa_circRNA_102958 may serve as a diagnostic marker for gastric cancer. Cancer Biomark 27 $139-145,2020$

105. Lan X, Cao J, Xu J, Chen C, Zheng C, Wang J, Zhu X, Zhu X and Ge M: Decreased expression of hsa_circ_0137287 predicts aggressive clinicopathologic characteristics in papillary thyroid carcinoma. J Clin Lab Anal 32: e22573, 2018.

106. Ren H, Liu Z, Liu S, Zhou X, Wang H, Xu J, Wang D and Yuan G: Profile and clinical implication of circular RNAs in human papillary thyroid carcinoma. PeerJ 6: e5363, 2018.

107. Shi E, Ye J, Zhang R, Ye S, Zhang S, Wang Y, Cao Y and Dai W: A combination of circRNAs as a diagnostic tool for discrimination of papillary thyroid cancer. Onco Targets Ther 13 : 4365-4372, 2020

108. Pegtel DM and Gould SJ: Exosomes. Annu Rev Biochem 88: 487-514, 2019
109. van der Pol E, Böing AN, Harrison P, Sturk A and Nieuwland R Classification, functions, and clinical relevance of extracellular vesicles. Pharmacol Rev 64: 676-705, 2012.

110. Yang C, Wei Y, Yu L and Xiao Y: Identification of altered circular RNA expression in serum exosomes from patients with papillary thyroid carcinoma by high-throughput sequencing. Med Sci Monit 25: 2785-2791, 2019.

111. Hsiao KY, Lin YC, Gupta SK, Chang N, Yen L, Sun HS and Tsai SJ: Noncoding effects of circular RNA CCDC66 promote colon cancer growth and metastasis. Cancer Res 77: 2339-2350, 2017.

112. Chen D, Ma W, Ke Z and Xie F: CircRNA hsa_circ_100395 regulates miR-1228/TCF21 pathway to inhibit lung cancer progression. Cell Cycle 17: 2080-2090, 2018.

113. Zeng K, He B, Yang BB, Xu T, Chen X, Xu M, Liu X, Sun H, Pan Y and Wang S: The pro-metastasis effect of circANKS1B in breast cancer. Mol Cancer 17: 160, 2018.

114. Sun JW, Qiu S, Yang JY, Chen X and Li HX: Hsa_circ_0124055 and hsa_circ_0101622 regulate proliferation and apoptosis in thyroid cancer and serve as prognostic and diagnostic indicators. Eur Rev Med Pharmacol Sci 24: 4348-4360, 2020.

115. Rüster B, Göttig S, Ludwig RJ, Bistrian R, Müller S, Seifried E, Gille $\mathrm{J}$ and Henschler R: Mesenchymal stem cells display coordinated rolling and adhesion behavior on endothelial cells. Blood 108: 3938-3944, 2006.

116. De Becker A and Riet IV: Homing and migration of mesenchymal stromal cells: How to improve the efficacy of cell therapy? World J Stem Cells 8: 73-87, 2016.

117. Nitzsche F, Müller C, Lukomska B, Jolkkonen J, Deten A and Boltze J: Concise review: MSC adhesion cascade-insights into homing and transendothelial migration. Stem Cells 35: 1446-1460, 2017.

118. Toh WS, Lai RC, Zhang B and Lim SK: MSC exosome works through a protein-based mechanism of action. Biochem Soc Trans 46: 843-853, 2018

119. Keshtkar S, Azarpira N and Ghahremani MH: Mesenchymal stem cell-derived extracellular vesicles: Novel frontiers in regenerative medicine. Stem Cell Res Ther 9: 63, 2018.

120. Kalimuthu S, Oh JM, Gangadaran P, Zhu L, Lee HW, Jeon YH, Jeong SY, Lee SW, Lee J and Ahn BC: Genetically engineered suicide gene in mesenchymal stem cells using a Tet-On system for anaplastic thyroid cancer. PLoS One 12: e0181318, 2017.

121. Milane L, Singh A, Mattheolabakis G, Suresh M and Amiji MM Exosome mediated communication within the tumor microenvironment. J Control Release 219: 278-294, 2015.

122. Tang M, Wang Q, Wang K and Wang F: Mesenchymal stem cells-originated exosomal microRNA-152 impairs proliferation, invasion and migration of thyroid carcinoma cells by interacting with DPP4. J Endocrinol Invest 43: 1787-1796, 2020.

123. Zhang C, Cao J, Lv W and Mou H: CircRNA 100395 carried by exosomes from adipose-derived mesenchymal stem cells inhibits the malignant transformation of non-small cell lung carcinoma through the miR-141-3p-LATS2 axis. Front Cell Dev Biol 9: 663147, 2021.

124. Yan B, Zhang Y, Liang C, Liu B, Ding F, Wang Y, Zhu B, Zhao R, Yu XY and Li Y: Stem cell-derived exosomes prevent pyroptosis and repair ischemic muscle injury through a novel exosome/circHIPK3/FOXO3a pathway. Theranostics 10: 6728-6742, 2020

125. Zhu M, Liu X, Li W and Wang L: Exosomes derived from mmu_circ_0000623-modified ADSCs prevent liver fibrosis via activating autophagy. Hum Exp Toxicol 39: 1619-1627, 2020.

126. Kamerkar S, LeBleu VS, Sugimoto H, Yang S, Ruivo CF, Melo SA, Lee JJ and Kalluri R: Exosomes facilitate therapeutic targeting of oncogenic KRAS in pancreatic cancer. Nature 546: 498-503, 2017.

127. Zarovni N, Corrado A, Guazzi P, Zocco D, Lari E, Radano G, Muhhina J, Fondelli C, Gavrilova J and Chiesi A: Integrated isolation and quantitative analysis of exosome shuttled proteins and nucleic acids using immunocapture approaches. Methods 87: $46-58,2015$

128. Yu LL, Zhu J, Liu JX, Jiang F, Ni WK, Qu LS, Ni RZ, Lu CH and Xiao MB: A comparison of traditional and novel methods for the separation of exosomes from human samples. Biomed Res Int 2018: 3634563, 2018 .

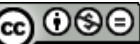

This work is licensed under a Creative Common Attribution-NonCommercial-NoDerivatives 4.0 International (CC BY-NC-ND 4.0) License. 